This is a post-peer-review, pre-copyedit version of an article published in Nature Energy. The final authenticated version is available online at: $\underline{\mathrm{http}} / / / \mathrm{dx} . \mathrm{doi} . \mathrm{org} / 10.1038 / \mathrm{s} 41560-020-00739-9$

https://www.nature.com/articles/s41560-020-00739-9

\title{
Time to rethink energy research
}

Elizabeth Shove, Professor of Sociology, Lancaster University. E.Shove@lancaster.ac.uk

Energy research works with units and concepts forged in an age of fossil fuel, leading to problem formulations that reinforce current societal practices and patterns of consumption. Achieving lowcarbon energy goals depends on shifting demand to match supply and reconceptualising interactions between time and energy.

The goal of substantially decarbonising the energy system has stimulated interest in renewable technologies, forms of storage and institutional and economic instruments for flexibly managing peak loads. Issues of time have also risen up the agenda, as the timing of energy demand must match the intermittent availability of renewable supply. These developments suggest that greater reliance on renewables calls for a major overhauling not only of infrastructures and systems of provision, but of how energy is conceptualized and understood. In essence, researchers and policy makers need to treat time and energy not as independent factors but as constructs that are densely interwoven with each other and with the nested time scales and rhythms of society.

In fields of physics and engineering, energy is treated as a quantifiable entity, measured in standardized units like joules, or millions of tonnes of oil equivalent. Time is treated similarly, thus so much energy is used over an hour or a day, summed up in composite units like the kWh. These familiar terms enable and are part of also familiar lines of enquiry. For example, methods of evaluating the relative efficiency of one technological solution compared to another depend on quantifying the amount of energy required to deliver a given service ${ }^{1}$. Methods of tracking national energy consumption also work with fixed units of time, such as measures of energy per capita per year.

As with all units, joules, seconds, days and years prioritise-some would say construct-qualities of the social and material environment and in the same move disguise and marginalize others. For example, clock time does not capture the experience of a day. When treated not as abstractions but as features of the world, standard metrics and the lines of enquiry that grow up around them acquire a life of their own ${ }^{2}$ : They become part of ongoing and largely taken for granted sequences of problem formation, data collection and analysis.

One practical consequence is that different energy sources (fossil fuels and renewable energy) are described in exactly the same terms. This has numerous advantages, making it possible to quantify the amount of wind or solar power produced during a day and to pin down the effects of fuel substitution over decades. However, these units are not well suited to other tasks, like revealing the subtle intersection of societal rhythms and the temporalities of supply and demand, or conceptualising their historical evolution over time. 
Up to now, this has not been an issue. In a world in which storable and seemingly limitless supplies of fossil fuel dominate, daily and seasonal fluctuations in demand are absorbed and overwritten. The unstated assumption is that contemporary ways of life depend on reliable and consistent systems of energy provision, 24 hours a day, all year round.

From an engineering perspective, the challenge of decarbonisation is to meet what are taken to be given societal needs and to do so more efficiently or with less carbon intensive fuels than before. Established metrics fit well with this approach, but they have the perverse effect of obscuring the scope for reconfiguring social and temporal rhythms and thus the timing of demand.

The result is a situation in which research that is ostensibly designed to reduce carbon emissions reproduces conventions and expectations born of an age of energy plenty. The following sections illustrate some of the blindspots that follow and consider ways out of this impasse.

\section{Daily variations in demand}

Programmes of demand side management are intended to modify the timing of peak load in order to reduce reliance on higher carbon forms of supply. Having used the clock and the meter to gather intelligence about when different activities occur, and how much energy they require, the next step is to persuade people to reschedule specific energy demanding practices like laundry or dishwashing to off peak hours. Analyses of this kind take no account of the broader temporal organization of daily life in which washing is embedded, or of trends in the sequencing and scheduling of work and leisure. This has implications for how problems are framed and for how they appear.

Efforts to estimate the contribution that electric vehicle charging could make to the broader goals of balancing load profiles and decarbonizing supply illustrate this point. Assuming that decarbonization is indeed the purpose, it makes sense to suppose that charging happens at night. However, this is not what people do. In daily life, clock 'hours' are not equal, rational economic action is overlain by the social value of time, and vehicle charging is isolated into already complex sequences and schedules.

The aim of optimizing energy systems has the rhetorical and practical consequence of classifying perfectly ordinary sociotemporal rhythms as 'non-technical barriers' and as obstacles to be overcome. Having assumed that electric vehicles would be charged at night, and having discovered that they are not, further research is then required to understand how appliances fit into diurnal rhythms and to identify ways of persuading people to change their ways ${ }^{3}$. In this example and in many others like it, standardized units of hours, costs and energy fail to capture, or even recognize, the differential valuing of evening activity, or the composition of week-days and week-ends ${ }^{4,5}$.

\section{Separation of supply and demand}

Another feature of conventional styles of analysis and enquiry is that supply and demand are conceptualized (and measured) separately. To some extent this is an obvious and in many ways necessary move. After all, no one would expect careful analysis of contemporary load profiles to reveal much about how patterns of daily life and systems and technologies of energy supply come to be as they are. However, few give further thought to how this obscures more challenging lines of enquiry. For instance, what might social and temporal rhythms be like if energy systems did not mimic the 'always on' template of the present, what if there was greater seasonal variation in patterns of work and leisure, and what if daily lives were organized around variations in energy supply? 
These might sound like outlandish suggestions, but historically people adjusted their energy demand to match availability from a variable energy supply ${ }^{6}$, and research has shown how social practices, their temporal organization and forms of energy supply evolve together ${ }^{7}$. In other words, there is nothing new about the interdependence of time-energy and social practice. What is new is the view that daily life should not be limited by natural rhythms ${ }^{6}$.

This is not to suggest some nostalgic return to the past. Rather, the point is that dominant paradigms in energy research and policy reproduce rafts of assumptions about the social world and such assumptions, and the metrics and methods associated with them, are real in their effects. Looking ahead, there is no reason to suppose that contemporary patterns of consumption will persist forever, nor is there reason to design systems and technologies that keep present conventions in place. In short, there are opportunities to imagine and actively engender societal rhythms that mesh with fluctuations in renewable energy supplies.

\section{Time scales of energy research}

Grasping these opportunities depends on thinking again about the timing of demand not as a separate topic but as something that is integral to the energy 'system' as a whole, and to how that changes. This is not what energy researchers usually do. They measure energy use over seconds, hours, days and years, depending on the focus of their work (see Table 1). The weight of research effort is not distributed equally across this spectrum, and temporal horizons change.

Table 1. Timescales adopted in different types of energy research.

\begin{tabular}{|l|l|}
\hline Research Topic & Unit of time \\
\hline Smart metering/internet of things & seconds \\
\hline Payment periods & minutes \\
\hline Evening peak/congestion & hours \\
\hline Hot water use & days \\
\hline Patterns of occupancy & days/weeks/week-ends \\
\hline Winter heating & seasons \\
\hline Summer cooling & seasons \\
\hline Appliance lifetimes/car fleet replacement & years \\
\hline Building lifetimes & decades \\
\hline Hydrogen economy & decades \\
\hline
\end{tabular}

However, the more important point is that the time scales across which energy research is defined and framed do not exist in isolation. Seconds are part of minutes, and seasons are part of years. What look like comparably massive 'turns', for instance from renewables (wind) to fossil fuels (coal), are made of overlapping trajectories, not all unfolding at the same rate and pace, and made up of different units (seconds, minutes) that are not equivalent but that are part of the period/s in which they are set.

This is obvious, but research problems are routinely carved out in ways that obscure these interactions and the threading together of past, present and future. Energy efficient building renovation is a good example in which the age of the building, the payback time on investment, the lifespan of the owner/occupier, and the durability of different materials interact ${ }^{8}$. 
Interventions in buildings and in energy systems occur within and as part of multiple dynamic processes that defy easy description, but that are crucial for conceptualising and fostering transitions not only in the types of fuels that are 'plugged' in to the supply system, but the timing of demand and thus in the making of a substantially lower carbon society.

Research agendas that focus on 'the' energy transition, and debates about how long this might take overlook this point. Given that energy systems (supply and demand together) are woven into society and into the constitution of always-changing sociotemporal rhythms there is unlikely to be any one such shift now or in the years ahead.

\section{Time for a paradigm shift}

Conventional methods of conceptualising and measuring time (seconds, hours, days, years) and energy (per capita, per year, per activity) sustain lines of enquiry that fail to engage with the sorts of challenges involved in reconfiguring the temporal organization of society. Units like the kWh tell us nothing about when energy is used, and alternative measures such as the kWhaPT (the kWh at peak time) or the kWhoPT (the kWh outside peak time) are not currently in use ${ }^{9}$. Other tendencies, such as focusing on the present, in isolation from the past; or investigating specific activities in isolation from the sociotemporal systems of which they are a part are symptomatic of currently dominant paradigms. Energy research needs to escape these limitations if it is to rise to the challenges ahead.

Some will argue that there is no need to modify societal rhythms and that new technologies whether of supply, storage or distribution will provide the technical fix that is needed. This sort of reasoning underpins ambitions like those of linking up European energy networks to enable 'gluts' of renewable energy (solar, wind, etc.) to be moved from one country to another. Despite being envisaged as part of 'the transition to a net-zero carbon society' and despite recognizing that such a transition implies 'a massive shift to weather-dependent renewable energy sources', the plan is to achieve that result without modifying current patterns of consumption ${ }^{10}$.

In seeking to meet existing needs, strategies of this sort are not neutral. They are performative and they actively help to sustain rhythms and patterns of demand that are systematically out of kilter with the temporalities of renewable energy supply. Resolving this tension and moving towards a lower carbon society arguably requires a paradigm shift: an upending of current agendas, and of many of the fossil-fuel based assumptions on which they depend.

This is not impossible. There is plenty of scope for adventure and innovation in energy modelling ${ }^{11}$. This could include anticipating the characteristics of much more seasonal economies, or flipping the problem around and imagining future ways of life that would produce load profiles aligned to the ebb and flow of wind and solar power at different scales. Amongst much else, this calls for fresh thinking about the meaning of 'flexibility': how it is constituted and where it lies ${ }^{12}$. There are already precedents to follow. For example, Torriti (2017) uses time-use data along with details of energy demand to describe variations in the ways in which combinations of practices change through the year ${ }^{13}$. Others are trying to piece together histories of seasonality, and to overcome the fact that annualized data flattens out what are likely to be hugely important trends. Similarly, in the field of energy 'transitions' there are ways of recognizing multiple threads of continuity, and of working with historians to better understand the layering and embedding of supply and demand as they change each other and as they change together. 
These are useful ways to go but for the moment they are running against the tide. That tide may turn, but until it does energy research will remain 'fossilised': unable to escape the past and constitutionally unable to engage with the challenges that lie ahead.

\section{References}

${ }^{1}$ Shove, E. (2017). "What is wrong with energy efficiency?" Building Research \& Information 46(7): 779789.

${ }^{2}$ Lutzenhiser, L. (2014). "Through the energy efficiency looking glass." Energy Research \& Social Science 1: $141-151$.

${ }^{3}$ Fang, Y., Asche, F. and Novan, K. (2018). "The costs of charging Plug-in Electric Vehicles (PEVs): Within day variation in emissions and electricity prices." Energy Economics 69: 196-203.

${ }^{4}$ Zerubavel, E. (1979). Patterns of time in hospital life : a sociological perspective. Chicago, University of Chicago Press.

${ }^{5}$ Torriti, J. (2015). Peak Energy Demand and Demand Side Response, Taylor \& Francis.

${ }^{6}$ De Decker, K. (2020). "Reorienting the Economy to the Rhythms of Nature: Learning to Live with Intermittent Energy Supply." American Journal of Economics and Sociology 79(3): 877-905.

${ }^{7}$ Nye, D. E. (1998). Consuming Power : A Social History of American Energies. Cambridge, Mass, The MIT Press.

${ }^{8}$ Fawcett, T. and Topouzi, M. (2019). The time dimension in deep renovation: evidence and analysis from across the EU. . ECEEE Summer Study. Belambra Presquile de Giens, France.

${ }^{9}$ Shove, E. (2017). "Energy and social practice: from abstractions to dynamic processes".in Complex systems and social practices in energy transitions: Framing the issue of energy sustainability in the time of renewables Labanca, N. Ed.^Eds. Cham, Springer International Publishing: 207-220.

${ }^{10}$ Gallo Cassarino, T. Barrett, M. and Sharp, E. (2018) A novel energy system model to find the optimal balance of storage and transmission using social and weather drivers. https://ieaetsap.org/workshop/gothenburgh_june2018/32-ETSAP_18062018_Tiziano.pdf

${ }^{11}$ McCollum, D. L., Gambhir, A., Rogelj, J. and Wilson, C. (2020). "Energy modellers should explore extremes more systematically in scenarios." Nature Energy 5(2): 104-107.

${ }^{12}$ Blue, S., Shove, E. and Forman, P. (2020). "Conceptualising flexibility: Challenging representations of time and society in the energy sector*." Time \& Society 0(0): 0961463X20905479.

${ }^{13}$ Torriti, J. (2017). "Understanding the timing of energy demand through time use data: Time of the day dependence of social practices." Energy Research \& Social Science 25(Supplement C): 37-47.

\section{Competing Interests}

The author declares no competing interests.

\section{Acknowledgements}

Elizabeth Shove gratefully acknowledges support from UK Research and Innovation through the Centre for Research into Energy Demand Solutions, grant reference number EP/R035288/1. 